\title{
The impact of an arts-integrated curriculum on student literacy and engagement
}

\author{
Rachel P. Feldwisch \\ Kristie L. Coker \\ Shanna M. Stuckey \\ Ashley A. Rittenhouse, \\ Kassi K. Kite \\ Joshua S. Smith
}

\begin{abstract}
This paper presents the results of mixed-method examination of the implementation and outcomes of the Arts Integration Program (AIP). The AIP was created by a national nonprofit organization that works with educational systems, the arts community, and private and public sectors to provide arts-related education to elementary school aged children. The arts-based literacy curriculum included an artist-in-residence component. The study design included classroom observations, interviews, and a pre-post standardized Literacy Assessment Tool in 11 schools in the Midwest. Results show high levels of student enthusiasm and engagement in the AIP, with consistently sustained levels of student engagement when the artists in residence facilitated learning. Student scores increased modestly in literacy knowledge, and the findings provide avenues for other schools to infuse arts into their literacy instruction.
\end{abstract}

\section{Introduction}

Embedding arts into literacy instruction fits naturally with many English Language Arts curricula across the country. The advent of the Common Core State Standards (CCSS) challenges schools and teachers to view the integration of subjects and move toward interdisciplinary lessons and units. This is consistent with prior research showing positive outcomes for arts-integrated learning among students at all grade levels going back to the 1990s. Eisner (1998) concluded that arts-integrated learning had the greatest academic impact when fine arts were integrated with language arts. Researchers have explored reasons why the arts benefit language arts learners (Cowan \& Albers, 2006; Csikszentmihalyi, 1990; Leland \& Harste, 1994), how learners benefit (Burton, Horowitz, \& Abeles, 2000; Heath, 2004), and the degree of benefit that can be achieved through arts-integrated learning (Burger \& Winner, 2000; Caldwell \& Moore, 1991; Smithrim \& Upitis, 2005; Trainin, Andrzejczak, \& Poldberg, 2006). While most authors agree that the arts should be appreciated for their own unique contributions to the development of the individual learner, many also see the arts as a potential catalyst for learning in other subjects (Eisner, 1998). 


\section{Theoretical Perspectives and Previous Research}

\section{The Influence of the Arts on Student Motivation and Engagement}

Theorists have suggested that mediators exist between communication through multiple sign systems and improved performance on measures of academic achievement. Csikszentmihalyi (1990) and Oldfather (1995) believed that motivation is the key to student engagement and subsequent academic performance. They suggested that artistic expression has motivated students to become more engaged in learning. Students who participated in visual art or music reported increased intrinsic motivation to pursue these endeavors, whereas students who pursued math or science reported very low levels of intrinsic motivation (Csikszentmihalyi, 1990). Csikszentmihalyi addressed the need for teachers to motivate readers toward literacy by making learning more rewarding and enjoyable. As Oldfather (1995) stated,

When students engage in authentic self-expression as part of their literacy activities, their learning processes become inherently connected to how they think, what they value, and who they are. They are able to become part of a community of learners that enriches and extends mutual thinking and ideas, and enhances their motivation for further engagement in reading and writing (pp. 421-422).

Oldfather's rationale could explain how educational programs that allowed students to express themselves using multiple modes of symbolic communication have motivated them to learn.

Burger and Winner (2000) concluded that children are more motivated to read and write after they are engaged in the process of creating visual art, but questioned whether other engaging activities would have the same impact on motivation. Similarly, Smithrim and Upitis (2005) evaluated the impact of the Learning Through the Arts (LTTA) curriculum by comparing data from LTTA students to control groups who participated in a technology integration program. They concluded that students' academic gains in mathematic computation were associated with engagement in the LTTA curriculum, and that these students performed better in computation than those who participated in a technologyintegrated curriculum because they were more engaged by the arts-integrated lessons.

\section{The Academic Impact of Arts-Integrated Learning}

Additional groups of researchers have provided evidence supporting the inclusion of the arts in literacy instruction. In their study of drawing as a precursor to narrative writing, Caldwell and Moore (1991) compared the written expressions of two groups of second- and third-grade students, one with arts-integrated literacy instruction and one with traditional language arts activities. They found that students who participated in drawing activities prior to narrative writing scored significantly higher on the Narrative Rating Scale compared to students who participated in discussions as a prewriting experience. In a subsequent study 
(Moore \& Caldwell, 1993), teachers combined drama and drawing as prewriting activities. The use of multiple sign systems also produced a better quality of written work than the traditionally prepared control group. Trainin, Andrzejczak, and Poldberg (2006) provided additional evidence linking the integration of art and writing to improvements in academic achievement on standardized language arts tests. These researchers found that second- through fifth-grade students $(\mathrm{N}=342)$ who participated in an arts integration program called Picturing Writing showed increased quality and quantity in their written work compared to control groups (Trainin et al., 2006). Recent research by Walker, Tabone, and Weltsek (2011) revealed that middle school students in an arts-integrated classroom were 77 percent more likely to pass the language arts portion of the New Jersey state standardized assessment when compared to students in a traditional classroom. The study compared testing outcomes in four schools with a traditional language arts curriculum to four schools with a theater arts-infused curriculum. These researchers also found a higher level of student engagement as evidenced by students' days absent from school: students in the drama-infused program missed fewer days of school $(M=5.51)$ than students in the control group $(M=6.3)$. The positive outcomes of these research studies supported the conclusion that students in elementary and middle school grades derived academic benefits from the integration of the fine arts and language arts.

\section{The Arts and Written Expression as Multiple Modes of Communication}

In contrast to the arts-integration view of the arts within literacy instruction, a group of literacy researchers who are also practicing artists have encouraged educators to see the interconnection between language arts and fine arts (Albers, Holbrook, \& Harste, 2010). This body of work focuses on multiple modes of communication interacting to form a new definition of literacy in education. Leland and Harste (1994) described the history of language arts education as "verbocentric," having been focused on written and oral language as opposed to other sign systems. They advocated for a view of literacy that incorporated "multiple ways of knowing for the purpose of ongoing interpretation and inquiry into the world" (p. 339). Drama, music, visual art, and mathematics were described as symbolic languages that expand student perspectives and understanding across the curriculum. Caldwell and Moore (1991) specifically identified drawing and writing as "two equally important symbol systems" that can support each other during the creative process (p. 207). Drawing was not only a precursor to students' development of written expression, but also presented a more individualized system of communication in that symbols were developed by the creators. Caldwell and Moore noted that the use of drawing as a planning strategy allowed young authors "to find a correspondence between internal and external representations of ideas" (p. 208). Cowan and Albers (2006) took the importance of symbols one step further, stressing the relationship between cognition and emotion during artistic and linguistic expression. In their discussion of the arts and writing as "semiotic representations," Cowan and Albers stated, "comprehension increases as cognition and affect are connected" (p. 134). Leland and Harste (1994) called for future 
researchers to explore the interaction of sign systems when the arts are integrated with literacy.

Theoretically, we agree with Albers and Harste (2007) that "a multimodal approach in teaching acknowledges, then, that language is only partial, and that many modes are involved in meaning-making, even though one mode may be chosen to represent meaning" (p. 11). The creators of the arts-integrated literacy program that is the focus of this study infused fine arts into a curriculum that emphasizes a multimodal perspective, yet their quantitative assessment addressed the more traditional view of language art-reading comprehension and English writing skills. As a result, we selected a mixed-methods design to explore both the quantifiable gains in traditional literacy skills and the qualitatively rich experiences of students engaged in multimodal literacy instruction.

\section{Research Objectives}

The purpose of this study was to understand the impact on student literacy of an arts-based literacy curriculum with an artist-in-residence component. The Arts Integration Program was designed by a national nonprofit organization (NPO) that works with educational systems, the arts community, and private and public sectors to provide arts education to children. The program was created to enhance reading, writing, and learning skills of children in kindergarten through eighth grade using an arts-infused curriculum that combines artist residencies with lessons taught by classroom teachers. Visual arts, dance, theater, music, and literary arts were integrated with best practices in literacy education to create a program that helps teachers meet state standards in language arts. Lessons are focused around wellknown literary pieces and involved between 12 and 18 hours of student instruction. The NPO created a standardized assessment tool, the AIP Student Literacy Assessment Tool (SLAT), to measure literacy gains among student participants.

The NPO enlisted researchers from the School of Education at a local university to conduct an evaluation of the AIP program for three school years. Researchers conducted an implementation fidelity study the first year and transitioned to a summative evaluation during the second and third years of the partnership. Using a mixed-method research model, the focus of the summative evaluation included analyses of the AIP's effects on students, the perspectives of teachers, and the contributions of the artists in residence. The guiding research questions for the summative evaluation were:

- To what extent do AIP lessons engage and interest students?

- To what extent do AIP classrooms exemplify teaching as modeled by the training and intent of the curriculum?

- After students have experienced AIP lessons, what is the impact on their literacy skills? 


\section{Method}

\section{Participants and Setting}

From 2009 to 2011, 11 statewide schools (one rural, eight urban, two suburban) participated in the research (see Table 1). The teachers participated in training sessions specific to the unit they implemented in their classroom. Fifty-one classrooms were observed during implementation of the AIP unit. Thirty teachers participated in interviews regarding their experiences with the AIP curriculum. Throughout the three years, all five units were implemented across the 11 sites. Students in these classrooms ranged from second through sixth grade. Four hundred and thirteen students completed the SLAT before and after program implementation during years two and three. However, results were only included from students with signed parental consent and student assent forms $(\mathrm{N}=43$ year two, $\mathrm{N}=190$ year three).

\begin{tabular}{|c|c|c|c|c|}
\hline School & Locale & $\begin{array}{l}\text { Free/Reduced } \\
\text { Lunch }\end{array}$ & $\begin{array}{l}\text { Students } \\
\text { Color }\end{array}$ & Enrollment \\
\hline 1 Rural & Small town & $49 \%$ & $0 \%$ & 93 \\
\hline 2 Suburban & $\begin{array}{l}\text { Urban fringe of } \\
\text { mid-size city }\end{array}$ & $47 \%$ & $39 \%$ & 974 \\
\hline 3 Suburban & $\begin{array}{l}\text { Urban fringe of } \\
\text { mid-size city }\end{array}$ & $46 \%$ & $30 \%$ & 584 \\
\hline 4 Urban & Mid-size city & $70 \%$ & $57 \%$ & 486 \\
\hline 5 Urban & Mid-size city & $86 \%$ & $50 \%$ & 254 \\
\hline 6 Urban & Large city & $77 \%$ & $81 \%$ & 388 \\
\hline 7 Urban & Large city & $54 \%$ & $57 \%$ & 338 \\
\hline 8 Urban & Large city & $35 \%$ & $41 \%$ & 312 \\
\hline 9 Urban & Large city & $85 \%$ & $63 \%$ & 454 \\
\hline 10 Urban & Large city & $86 \%$ & $86 \%$ & 341 \\
\hline 11 Urban & Large city & $68 \%$ & $60 \%$ & 213 \\
\hline
\end{tabular}

Table 1. 2009-2010 Demographic Data of Participating Schools

Classroom assignment of the AIP curriculum within school systems was decided by the national program prior to the initiation of the research study. The national program requested data regarding all participants; therefore, our sample was essentially predetermined. While all students in the selected classrooms participated in the AIP curriculum, students were self-selected to participate in the research study. Principals signed permission for classroom observation and gathering of data, and teachers signed consent forms prior to interviews. However, students' assessment data was not included without a signed consent from parents and assent from students.

\section{Measures and Procedures}

Observations. Researchers conducted observations in 51 classrooms in 11 different schools. During each classroom observation session, extensive field notes were taken by an outside observer who focused on interactions between teachers and students, students' level of engagement with the AIP curriculum, and the teachers' 
fidelity to implementation of the curriculum. Researchers scheduled visits according to the teachers' schedules and intentionally observed a variety of experiences, including teacher-instructed lessons, cooperative learning exercises, artist-inresidence visits, and final performances. Semistructured observations were conducted for the entire AIP lesson. Observers sat at the back or side of the room, noted the characteristics of the room, took copious notes during the lesson, and immediately noted any emergent hypotheses or assessments after each observation.

Interviews. Thirty teachers took part in interviews, lasting approximately 30 minutes each, following the completion of the AIP curriculum. General program impressions and recommendations for improvement were the main focus of these interviews. Sample prompts included "Describe the atmosphere you created while conducting lessons," "Tell me how the AIP training you received prepared you for the process," "Describe your feelings about the artist residency portion of the program," and "Discuss your feelings about the AIP program in general. What went well? What would you like to change?" Interviews were transcribed verbatim in preparation for analysis.

Literacy assessments. The AIP Student Literacy Assessment Tool (SLAT) was administered before and after completion of the AIP unit during years two and three. As the NPO's tool for assessing literacy gains for students across the nation, the SLAT has been used in classrooms across the United States for the last four years. To complete the assessment, students read a short biography about the American socialite Ruth Harkness, and then answered nine to twelve (depending on the version of the assessment) open-ended questions, most of which included a series of subquestions. Sample questions included "How would you describe Ruth's personality? List as many character traits as you can. Support each trait with an example from the biography," and "If you were watching a movie of Ruth's life, what are some sounds that you might hear? Use words or phrases from the biography to support your answer." In year two, the assessment consisted of twelve questions with varying point values, with student scores ranging from 12 to 49 . In year three, changes were made to the assessment by the NPO and the number of questions decreased to nine, with student scores ranging from 2 to 42 .

\section{Data Analysis}

Qualitative data. Transcribed observations, open-ended survey items, and verbatim transcripts from audiotaped interviews were entered into NVIVO qualitative software. Researchers applied codes representing the sentiment of each paragraph or data cluster and/or developed codes identifying patterns within the data. As a group, the team met to discuss the relationships among codes and to combine similar codes into broader patterns or themes. Next, they divided into groups in order to return to the original data sources to identify representative examples from observations and quotations from interviews. Finally, the entire team met to share findings, which resulted in specific themes. This type of cooperative work among qualitative research teams creates an overall better understanding of the data and leads to more valid conclusions (Creswell, 2007). 
Quantitative data. Students who completed both pre- and post-assessments were included in the statistical analysis. Scores on the SLAT pre- and post-measures were analyzed using SPSS. A paired-samples $t$-test was conducted to examine any differences in student scores between the pretest and post-test.

\section{Results}

Overall, the AIP program was viewed as an asset in the classroom and its implementation was related to improvements in student learning. Several trends emerged from the data, including student engagement and motivation, student gains, student challenges, and teacher perspectives.

\section{Student Engagement}

Literature regarding the impact of arts-infused programs on literacy learning touts an increase in student engagement and motivation for learning (Arts Education Partnership, 2004; Caldwell \& Moore, 1991; Upitis \& Smithrim, 2003). Consistent with this literature, students were described as highly motivated and engaged during AIP lessons. Behaviors typifying engagement included maintaining eye contact, refraining from off-topic talk during direct instruction, participating appropriately in activities, and displaying excitement about the curriculum in the form of smiles, eager tones, and active participation. As one teacher commented, "It was fun. It was engaging. It was wonderful to see all kids wanting to be a part of it." The theme of engagement and motivation was further defined as enthusiasm, student collaboration, and self-expression.

Enthusiasm. Student enthusiasm was a noticeable indicator of engagement in the AIP lessons. During and after classroom observations, teachers spoke directly to researchers about student involvement, indicating, "The kids just love this," and "[Students] really get into the lessons." Elevated and animated tones exemplified the anticipatory excitement of students when beginning their AIP lessons. Speaking to the eagerness of her students, one teacher commented, "The kids looked forward to doing it. So that made it so happy for everyone ... Everybody is excited, clearing things off [their desks] so they could get on it." In another classroom, students expressed excitement when the teacher told them they were moving from the current lesson to the AIP lesson on motifs, a curriculum component from the music unit. Students rushed to grab instruments composed of common classroom items, such as rulers and pencil boxes. When a teacher asked her fourth grade classroom if they would like to do AIP again in fifth grade, an overwhelming majority of students affirmed that they did. Other students learning the theater curriculum were particularly excited when their teacher offered herself as a prop for the drama performance. The entire classroom laughed and smiled as the teacher curled into a ball on the floor while the narrator introduced the scene and the audience discovered that she represented a rock.

Student volunteers were never in short supply during AIP lessons. While students were noted as being more apprehensive during the early stages of AIP, there were times when almost every student volunteered during a single period. 
Students bounded from their chairs and waved their arms frantically in the air to provide an answer. In one classroom, a female student volunteered to give up her time in "specials" class to show one researcher her collage and discuss her revision process.

Involving professional artists in the classroom experience has been associated with enriched learning for students (Arts Education Partnership, 2004; Deasy, 2002). According to the Arts Education Partnership (2004), residencies "can intensify the learning experiences of students, add to the skills repertory of teachers in schools, and improve the pedagogy and classroom management skills of participating artists" (p. 21). Student engagement was more pronounced during artist residencies as compared to their behavior during lessons taught by their classroom teachers. Each artist's enthusiasm for his or her artistic medium was contagious, as evidenced by students' excited facial expressions, the number of hands that were raised when an artist asked a question, and the number of students who danced along with the music, moved into position for a performance, used their most animated warm-up theatre voice, or cut and pasted onto a collage with noticeable enjoyment. One teacher described the power of these partnerships during her interview:

The artist who came in was amazing. It makes me smile just thinking about it because he was so personable, so kind. He knew his thing. He did such a great job with the kids. He reached out. He got kids to do things that you know they just don't always get the opportunity to do and it was amazing.

Teachers repeatedly commented on the excitement of their students at having a "real" artist in the classroom. Students were eager to learn from the artist and felt privileged to be working with professionals. One teacher noted students' particular excitement through drawings she continued to see once the artist was gone. She reported,

The kids were super excited about having an artist come in. She did a wonderful job, and I still see palm trees and monkeys on their assignments and stuff all the time ... It is really nice to get the art bug into their bodies.

Collaboration. A high level of student engagement was evident the majority of the time during observations of structured group collaboration. Student collaboration occurred in the forms of intentionally constructed group activities and naturally occurring interactions between students. For example, fifth grade students participating in collaborative poetry groups were observed working together and working through disagreements. The younger students participating in theater activities initially struggled with collaborative work as each group member fought to play the main role. However, as the lessons progressed, students became better able to divide roles and work together to achieve their common purpose. Students engaged in collages sought feedback from fellow students and incorporated suggestions as they revised their artwork. One teacher reported an increase in student enthusiasm regarding their performances after working together in groups. When working as a group, one student enthusiastically said, "I'll be the director. Or 
at least say director lines." With enthusiasm, a female student exclaimed, "Y'all, let's do it again," as she rounded up her group members to reenact the scene. When moving into the second scene, the student muttered a unit vocabulary word, "level," under her breath to remind the actor as the student crouched and smiled in response to the suggestion. The group of students then gave each other high-fives after practicing the scene.

Teachers also asked students to collaborate regarding written work, and this cooperative learning helped them to gain a better understanding of the material. During group work, students adjusted their answers in their student notebooks, asking each other questions, and providing feedback to their peers.

Self-expression. Educators perceived that student engagement was related to opportunities for self-expression during AIP lessons. Teachers gave several examples of times when the particular art medium evoked expression from students who were typically resistant to traditional verbal forms of communication. A teacher using the theater unit in her classroom noted:

In terms of the [acting aspects] and all of that, that was amazing. They loved it. I loved it. I fully intend to use it with other books. The nice part is I saw so many kids who are typically introverted children really love it.

One educator spoke about a male student who "gets stuck and very frustrated and he just refuses to write." However, when he served as a narrator for his scene, the student was able to express himself in a new way that became a source of pride and accomplishment. Another teacher noted a similar outcome from a female student working in the theater unit, "I have one girl who barely speaks and she got the one speaking part. Her mom was just beaming because she is known for not talking."

Several teachers pointed out that the artistic media contributed to overall student enthusiasm. Speaking to her experience with the dance unit, one teacher noted, "The music was very helpful to go along with the words. That kind of loosened up that free-flowing spirit for the students." Teachers working with the collage curriculum noticed student enthusiasm related to the artistic process. One teacher stated, "It was neat to see them get excited about how they used the arts to promote some of those ideas, pieces from the story."

Student self-expression was most obviously evidenced by their final products. For example, fourth grade students proudly displayed collages and chatted excitedly as they hung them in a hallway for all students in the school to see. Fifth graders studying the dance unit rehearsed for their final performances, which featured a wide variety of music, movements, and subject matter, while another group of fifth graders hosted local NPO staff when they performed their original music compositions at the conclusion of the unit. During each of these instances, students were uniquely inspired by the curriculum and noticeably excited about their creations. Teachers, parents, and other adult observers repeatedly stated how impressed they were by the depth and breadth of students' self-expressions. 


\section{Student Literacy Gains}

Both quantitative and qualitative measures were used to assess the academic gains of students participating in the AIP program. The SLAT provided a quantitative measure of student gains during years two and three, while observations and interviews provided a qualitative basis for gauging student learning. After improvements were made to the assessment by the NPO, the number of questions decreased from twelve in year two to nine in year three, which is reflected in the whole sample mean scores for each year. The mean score for pretests for the 20092010 school year was $M=28.98, S D=9.20$, and the mean score for post-tests was $M$ $=32.98, S D=8.90$ (See Table 2). The mean difference between the pretest and posttest for this sample was -3 points. The $t$ score for this data was $t(42)=-1.51$, indicating that the 2009-2010 results of the SLAT were statistically significant at $\alpha=$ 0.10 . Cohen's $d=0.435$, indicating an effect size that was just below the medium or moderate category.

\begin{tabular}{lll} 
& Total Scores & \\
& Pre $(\mathrm{N}=43)$ & Post $(\mathrm{N}=43)$ \\
\hline $\mathrm{M}$ & 28.98 & 32.98 \\
\hline$S D$ & 9.20 & 8.90 \\
\hline & & \\
${ }^{*} \mathrm{p}<0.001$ &
\end{tabular}

Table 2. Mean Total Score Comparisons 2009-2010

The mean score for pretests for the 2010-2011 school year was $M=18.91$, $S D=9.67$, and the mean score for post assessments was $M=21.66, S D=8.66$ (see Table 3). The mean difference between the pretest and post-test for this sample was -2.75 points. The $t$ score for this data was $t(178)=-0.74$, indicating that the results were not statistically significant at $\alpha=0.10$. Cohen's $d=0.28$, indicating that the effect size was small. Overall, students showed an increase in literacy skills following their completion of the AIP program, but results were more significant during the 2009-2010 school year compared to the 2010-2011 school year.

\begin{tabular}{|lll} 
& Total Scores & \\
& Pre $(\mathrm{N}=179)$ & Post $(\mathrm{N}=190)$ \\
\hline $\mathrm{M}$ & 18.91 & 21.66 \\
\hline$S D$ & 9.67 & 8.66
\end{tabular}

${ }^{*} \mathrm{p}<0.001$

Table 3. Mean Total Score Comparisons 2010-2011

In addition to assessment results, observed evidence of student gains included vocabulary acquisition, oral communication, and achievement of unitspecific goals. Students were observed learning the AIP vocabulary words during large group instruction and practicing application of the vocabulary in small groups. During interviews, teachers stated that the new vocabulary words would be used in subsequent lessons, including lessons in other subject areas. The uniformity and 
depth of vocabulary development brought to those discussions and activities were noted as additional evidence of student gains.

Several teachers reported gains related to both oral and nonverbal communication, which were not tested by the SLAT. According to one teacher whose students studied dance, they "learned a great deal about creating a performance and performing." Educators also mentioned the growth that occurred as students learned how to express their needs and opinions within a group. Researchers observed small group interactions in classrooms and witnessed students dividing tasks, making decisions, working through disagreements, and forming compromises, especially towards the end of units after students had a chance to adapt to working closely with their peers.

\section{Student Challenges}

Student challenges varied according to unit and grade level. Second graders working on aspects of the theater components of AIP expressed frustration regarding written exercises. Fourth grade students who completed collages were frustrated when asked to repeatedly revise their work. Most teachers believed that students benefited from learning about rewriting and revision, but they also felt that the repetitive nature of the revision process was a challenge for students. As one teacher noted:

To revise the collage in fourth grade was very frustrating to the concrete thinkers in my classroom - "I did what you asked, why change it?" The abstract/creative thinkers enjoyed the process, but sometimes were frustrated with the revision as well.

While concerns regarding repetition during the revision process seemed unique to the collage unit, several teachers mentioned that their students found the student notebooks to be redundant during other units. It was hard for the second and third graders studying theater to work through the question-and-answer process multiple times for multiple stories, and both fourth and fifth graders were frustrated by repetition of the same subject matter in the collage and music units. Some teachers suggested that shortening the amount of time spent on AIP written material may have decreased student boredom, while others suggested using a greater diversity of material within a single unit.

Students were also frustrated by the SLAT that occurred before and after the unit. Due to the complexity and length of the test, students often did not finish the assessment. Some of the factors that influenced student frustration included the difficulty of the material (i.e., above grade level), the lack of correspondence between the assessment and the unit concepts, and the repetitive nature of the preand post-test. Several teachers also reported administering the test close to the state standardized test, which may have contributed to some student aggravation. 


\section{Teacher Perspectives}

Albers and Sanders (2010) noted that teacher comfort level, collaboration, and "buy-in" are important factors when introducing a multimodal literacy curriculum such as AIP. Teachers' overall appraisal of the AIP units was consistently favorable, as many stated that both educators and students benefited from the program. "I loved the program," stated one teacher. "We all learned a little about ourselves. We were able to come out of our comfort zone." Many educators shared similar comments: "You have a great curriculum and philosophy ... myself and my students greatly benefited from this unit." Beyond student literacy gains, additional benefits included students learning about performance, teachers gaining new ideas regarding integrating arts across the curriculum, and everyone enjoying the artistic processes and products. One teacher enthusiastically stated that the AIP Curriculum "gave me lots of new ideas and overall, just a great experience-I am a big supporter!"

Teacher fidelity to AIP curriculum. In general, educators approached the curriculum in ways that aligned with the AIP unit guides. Classroom teachers described strict adherence to the model when they first introduced the curriculum to students. They consistently used vocabulary and concepts during instruction that were provided by AIP for each specific unit. Several teachers mentioned making adaptations and adjustments to the curriculum as they progressed through their units, such as adapting lessons to their own teaching style, adjusting the length of the lessons, or incorporating outside resources to meet the needs of their students. While teaching the collage unit, one teacher brought in a parent who is a successful collage artist to speak with her class. Educators felt more comfortable modifying the lessons as they progressed through the curriculum and became more familiar with the unit-specific content.

Teacher collaboration and support. Teachers described collaboration with other educators, which included art teachers, music teachers, a Spanish teacher, and general education teachers. Visual and performing arts teachers were widely viewed as a resource for assistance and advice when general education teachers integrated the arts with literacy. At the conclusion of the units, several teachers invited students from other grade levels to be the audience for final performances. In this way, students from other grade levels were exposed to the AIP curriculum despite not receiving direct instruction using the AIP lessons.

Administrators and parents consistently supported the AIP program in schools. Throughout the program, administrators supported teachers by viewing displays of artwork, attending final performances, and visiting classrooms during implementation of the lessons. Parents participated by talking with their children about the units, sending in art materials, returning permission slips, and attending events such as the final performances. Several teachers received positive feedback directly from parents by email and in person following performances. 
Concept transfer and application. Evidence of teacher buy-in included teachers reporting reuse of AIP strategies in subsequent lesson plans and transfer of arts-integrated learning to other subjects. Concept transfer was not directly observed by researchers because all observations were intentionally conducted during AIP lessons. Transfer of AIP vocabulary, concepts, and artistic media to other lessons and contexts emerged as consistent themes when teachers explained the impact on student learning. Several teachers expressed plans to implement interdisciplinary lessons, integrating the arts with other subject matter using strategies learned through their AIP experiences. One educator mentioned rewriting science and social studies curricula during their summer mapping sessions, to include concepts from the units. Another teacher told a story about a student who integrated the arts with the science curriculum on his own, following the dance unit:

We did a science project and one of the students came in with a big collage with different things from the environment and put it on a nice, big wooden display board. So then I knew that the kind of work we've been doing generated that thinking.

Teacher challenges. While many teachers commonly integrated arts into their lessons and felt comfortable doing so, others reported being outside of their "comfort zones" and had to adjust to new and different teaching methods. A few of the challenges reported by teachers were specific to their particular grade level. For example, the second grade teachers repeatedly mentioned that the written material and exercises for the theater unit were "too difficult" for their students, and they had to modify the curriculum (i.e., writing group responses on the overhead for students to copy instead of working individually). Other challenges were unitspecific, such as one teacher's suggestion that the dance unit include literature from more ethnically diverse poets, as well as more opportunities for students to use prosody.

Suggestions offered to improve the program included allocation of time and scheduling of lessons. Teachers felt that the timeline in the teacher guide provided by the NPO did not match the actual amount of time needed to conduct the lessons, and should be adjusted to allow additional minutes of instruction. Educators also commented on the timing of implementing the unit within the school year. Some teachers were still conducting lessons during the final days of school, and fifth graders at one school were headed to their end-of-year celebration right after their final AIP performances. Scheduling units close to the end of the school year seemed to add stress to teachers, who repeatedly mentioned to researchers that they were tired, and in some cases, overwhelmed.

Another challenge for teachers pertained to the SLAT. Some teachers felt the assessments were not at an appropriate level for the grade they were teaching and felt challenged by the amount of time required to complete the assessment. They did not like administering the assessment, and several felt that it was a waste of time. Other criticisms included the lack of answer lines, unclear questions, and the use of the same essay in both the pre- and post-test. 


\section{Discussion}

The results suggest that the AIP program was generally implemented as intended, had strong support from classroom teachers, and was enjoyed by students. Extensive teacher training, coupled with assistance from professional artists through the residency program, empowered teachers to utilize the arts as a vehicle to promote enjoyable, engaging student literacy learning.

In the existing literature, cognition and motivation are the two most commonly cited benefits of integrating the arts with literacy instruction (Burger \& Winner, 2000; Trainin et al., 2006). Quantitative analyses in the current study revealed statistically significant gains in literacy skills during year two, and high levels of student engagement were consistently observed during AIP lessons. These findings align with the body of research on student learning through arts-integrated programs. In addition, Burton, Horowitz, and Abeles (2000) suggested that the cognitive benefits of the arts and other areas of learning are dialectical, with academic skills being enhanced by the interaction of various educational experiences. In other words, one cannot assume that arts instruction has enhanced literacy instruction without literacy instruction having enhanced arts instruction. Symbolic communication and motivation could share a similar dialectical relationship. As Heath (2004) observed, "Much of the learning within the arts is described by young learners as "play'” (p. 340). Children have been engaged by the opportunity to create using other sign systems, while the pure "fun" of the experience has motivated children to communicate in and through the arts. Beyond sheer enjoyment, perhaps students were motivated by the opportunity to express themselves in multiple ways, leading to the "multiple ways of knowing" described by Leland \& Harste (1994, p. 337).

\section{Limitations}

To maintain consistency across programs, the national NPO enforced specific guidelines for implementation, such as the teacher guide and the instruments used for evaluation. One challenge with these mandated instruments was the inflexibility to make adaptations based on local needs. In addition, the NPO made changes to the instruments each year because of the growth, development, and desire to establish best practices. While these modifications are ultimately beneficial, this limited the ability to compare data across the first three years. We also question whether the changes made to the SLAT during year three caused the instrument to be less sensitive to student gains, impacting results.

Coordinating multiple schedules across different schools was a challenge. In addition, coordination of communication between the NPO, the teachers, and the evaluators was at times difficult due to varying schedules and multiple priorities from all stakeholders involved. Likewise, obtaining consent and assent from students and their parents participating in the AIP program emerged as a challenge, primarily due to misconceptions regarding the consent process by teachers and parents. Due to the constraints mentioned above, a limited number of pre- and postliteracy assessments were administered, scored, and analyzed. Conclusions drawn 
from this sample regarding literacy gains, therefore, are limited in scope and generalization. Further, significant gains reported on the pre- and post-tests in year two cannot be causally attributed to the AIP curriculum, due to the lack of a control group to account for history and maturation effects. Future research could employ a quasi-experimental design study utilizing classrooms receiving the AIP curriculum as an experimental condition, and those using the traditional literacy curriculum as comparison groups. The matched classrooms would be identified within the same school, and statistical controls would be applied to account for differences in teacher and student demographics. In addition to examining differences in literacy assessment scores, future research should examine student affect, including attitude toward reading/writing and interest/liking school.

\section{Implications for Practice}

The experience of documenting teaching and learning as schools integrated the arts into literacy instruction presents a counternarrative to the direct instruction movement in ELA of the early 2000s. The approach more closely aligns with the CCSS and the expectation for elementary generalists to integrate curriculum. Instead of restricting or narrowing the curriculum in preparation for high-stakes exams, these schools opened the curriculum and connected literacy to the lived experiences of children in the classroom. Inviting art professionals to serve as coteachers further expanded notions of the curriculum experts and pedagogical content knowledge. Teachers gained a set of skills, and students had the chance to explore their creativity. Exploring new ways of thinking and having the "freedom to fail" when the first ideas did not work out as planned provided opportunities to build persistence and internal motivation (Csikszentmihalyi, 1990). The AIP curriculum, the pedagogical guidance by the teacher, and the artist facilitated process-generated short-term successes and opportunities for students to produce knowledge.

The implications for literacy education cannot be understated in this regard. The pressure to increase test scores in English/Language Arts has resulted in a skills-based, phonemic awareness-focused environment in the early years of schooling (Walker, Tabone, \& Weltsek, 2011). Teachers feel pressured to increase vocabulary, hone sentence structure, and help students write the perfect fiveparagraph response to a set of story questions. The evaluation results here suggest that these important skills need not be the curricular anchor, but rather the supporting skills to an engaging literacy curriculum that is built around a particular genre of the arts. The fact that test scores increased only buoys the support for teachers to take the necessary risk of changing how literacy is done in today's schools. Teachers need solid evidence to approach curriculum directors and principals about moving away from basal readers and more static skill-based instruction, impelling them toward a multimodal approach to language arts education (Albers \& Sanders, 2010). Reaching outside of the general education classroom, the findings provide support not only for arts integration but also for increased connections between community arts education and literacy instruction. When the arts and literacy were integrated through the AIP lessons program, 
students became literate in more than one method of communication, gaining knowledge while also imparting knowledge, as educators gained a better picture of students' worldviews.

\section{References}

Albers, P., \& Harste, J. C. (2007). The arts, new literacies, and multimodality. English Education, 40(1), 6-20.

Albers, P., Holbrook, T., \& Harste, J. C. (2010). Talking trade: Literacy researchers as practicing artists. Journal of Adolescent \& Adult Literacy, 54(3), 164-171.

Albers, P., \& Sanders, J. (2010). Literacies, the arts, and multimodality. Urbana, IL: National Council of Teachers of English.

Arts Education Partnership. (2004). The arts and education: New opportunities for research. Retrieved from Arts Education Partnership website, http://www.aep-arts.org/files/publications/OpportunitiesResearch.pdf.

Burger, K., \& Winner, E. (2000). Instruction in visual art: Can it help children learn to read? Journal of Aesthetic Education, 34(3-4), 277-293.

Burton, J. M., Horowitz, R., \& Abeles, H. (2000). Learning in and through the arts: The question of transfer. Studies in Art Education, 41(3), 228-257.

Caldwell, H., \& Moore, B. H. (1991). The art of writing: Drawing as preparation for narrative writing in the primary grades. Studies in Art Education, 32(4): 207219.

Cowan, K., \& Albers, P. (2006). Semiotic representations: Building complex literacy practices through the arts. The Reading Teacher, 60(2), 124-137.

Creswell, J. W. (2007). Qualitative inquiry and research design: Choosing among five approaches. Thousand Oaks, CA: Sage.

Csikszentmihalyi, M. (1990). Literacy and intrinsic motivation. Daedalus, 119(2), 115-140.

Deasy, R. (Ed.). (2002). Critical links: Learning in the arts and student academic and social development. Washington, DC: Arts Education Partnership.

Eisner, E. W. (1998). Does experience in the arts boost academic achievement? Arts Education Policy Review, 100(1), 32.

Heath, S. B. (2004). Learning language and strategic thinking through the arts. Reading Research Quarterly, 39(3), 338-342.

Leland, C. H., \& Harste, J. C. (1994). Multiple ways of knowing: Curriculum in a new key. Language Arts, 71(5), 337-345.

Moore, B. H., \& Caldwell, H. (1993). Drama and drawing for narrative writing in primary grades. The Journal of Educational Research, 87(2), 100-110. 
Oldfather, P. (1995). Commentary: What's needed to maintain and extend motivation for literacy in the middle grades. Journal of Reading, 38(6), 420422.

Smithrim, K., \& Upitis, R. (2005). Learning through the arts: Lessons of engagement. Canadian Journal of Education, 28(1-2), 109-127.

Trainin, G., Andrzejczak, N., \& Poldberg, M. (2006). Visual arts and writing: A mutually beneficial relationship. Arts \& Learning Research Journal, 21(1), 139-155.

Upitis, R., \& Smithrim, K. (2003). Learning through the arts: National assessment final report. Toronto, Can.: The Royal Conservatory of Music.

Walker, E., Tabone, C., \& Weltsek, G. (2011). When achievement data meet drama and arts integration. Language Arts, 88(5), 365-372. 